S sciendo

\title{
Professor Whatever
}

Critical Notice of Kant and the Platypus: Essays on Language and Cognition, by Umberto Eco

Simon Blackburn

University of North Carolina, Chapel Hill

Disputatio No. 8

May 2000

DOI: $10.2478 /$ disp-2000-0004

ISSN: 0873-626X 


\title{
PROFESSOR WHATEVER
}

\author{
Simon Blackburn
}

Kant and the Platypus: Essays on Language and Cognition, by Umberto Eco. Translated by Alastair McEwan. Harcourt Brace and Company, 464 pp.

The title of Umberto Eco's new book gives due advertisement of his trademarks: high themes, arcane learning, strange corners of philosophy and history and natural history, large intellectual vistas, a sense of play. Readers excited by these prospects will probably already be familiar with The Name of the Rose or Foucault's Pendulum. They should be warned that the intellectual temperature is here supposed to be much higher. In Kant and the Platypus, Eco reverts to his academic interest in semiotics, or the theory of signs and communication.

His new book makes no concessions. It takes the reader into difficult writers, such as Heidegger, Kant and Peirce, and into their worst parts. Eco has been reported as saying that "This a hard-core book. It's not a pageturner. You have to stay on every page for two weeks with your pencil. In other words, don't buy it if you are not Einstein." Such braggadocio-call it Eco-terrorism - certainly fits the book, which is clearly the work of a person in whom the sense of doubt is less developed than other ambitions, such as cutting an intellectual figure, or appearing as something of a priest or a magus.

Eco's book resists classification, like the platypus of the title. It is not a work of philosophy, or scholarship, or cognitive science, though it bears resemblances to works in those fields. Unlike, say, Alice in Wonderland, it is not an entertainment, though it is entertaining in some places, and in many places it tries to be so. Like the platypus, it comes across as a bit of this and a bit of that. Its character is captured by the publisher's disclaimer: "Forgoing a formal, systematic treatment, Eco engages in a series of explorations...." But this is a little disingenuous: it gives the impression that a formal systematic treatment of something is just around the corner, extant even, but that Eco modestly hesitates to give it to us.

In truth, however, it is hard to imagine what has been forgone. Eco is not a man who concentrates on one thing at a time, which is presumably a

"Published with the kind permission of The New Republic. 
precondition of formal and systematic thought. He is a polymath who likes to impress and to sidetrack his readers; and the topics tumble over one another and compete for attention. I nearly said that we are watching the flight of the butterfly, not the stoop of the hawk; but both those creatures fly in the clear air, whereas here we are in the swamps, and much of the time we are close to suffocation. After some passages you might manage a wry smile, but generally speaking Eco's warning not to buy the book is sound, whether or not you are Einstein.

It is fair to start with the more positive side. This is the book of a very clever man who has read enormously. The individual chapters or essays give the impression of contributing to the discussion of serious philosophical problems. And when Eco allows us to come up for air, we often find ourselves pretty much on the side of the angels. He has noticed, for example, that it is not true that anything goes. There is a real world that, even if it admits of different descriptions or interpretations, nevertheless offers "lines of resistance" to false or inadequate thinking. If there is a boulder in your path and you fail to perceive it, things go worse; and they go worse in ways painfully apt to show what is wrong with the idea that there is nothing beyond the text. You know reality when you come up against it. Language, as Eco puts it, does not create being ex nihilo.

It is sad that all this still needs to be said, and it is well worth remembering that even the idealist Berkeley said it. Still, given that there are precincts of the academy in which truth and reality are endangered species, it is good to find a large-scale intellectual such as Eco getting this right. Incidentally, Eco's notion of resistance pleasantly echoes the motto-Les choses sont contre nous, "things are against us"-of the "resistentialist" school of philosophers invented by the humorist Paul Jennings. In Jennings's droll account, the French derived this by remorseless logic ('From this it follows, or it does in the French...'), whereas the empirical English established it by dropping pieces of buttered toast on carpets, and finding that the toast fell buttered side down with a frequency in direct proportion to the value of the carpet. Eco thinks, more portentously, that resistance is a manifestation of Being-or, as one might say less gravely, it is just one of those things.

Eco can also be good about the constraints on interpretation-as one might again expect, given that Foucault's Pendulum was a long allegory on the idiocy of unconstrained frenzies of taking one thing as a sign of another. The problem with that book was that the skepticism was muted. It required of us a lot of devotion to numerology, the Kabbalah, the Protocols of the Elders of Zion, the Knights of the Rosy Cross, and the rest of the menagerie before we were permitted to dismiss them, and even then the permission was curiously half-hearted. In his new book, Eco is more forthright, perhaps abjuring a wilder youth.

Indeed, the most philosophically interesting part of the book is Eco's defense of the rocks of genuine fixed meaning that stay put among the seas of reinterpretation. He reports a debate with Richard Rorty, who had alluded 
to the right that we have to interpret a screw-driver as something useful for scratching our ears, and Eco's reply is surely exemplary:

A screwdriver can serve also to open a parcel (given that it is an instrument with a cutting point, easy to use in order to exert force on something resistant); but it is inadvisable to use it for rummaging about in your ear precisely because it is sharp and too long to allow the hand to control the action required for such a delicate operation; and so it would be better to use not a screw-driver but a light stick with a wad of cotton at its tip.

It may be hard to believe that Rorty has really got himself into a state in which it would seem strange that a plumber carries tools different from those of a doctor. Perhaps he has. Perhaps pragmatism has come to this. In any event, as J.L. Austin once remarked, there is always the bit where you say it and the bit where you take it back.

Eco is also deft on truth in fiction, as in this passage:

It has been said that narrative worlds are always little worlds, because they do not constitute a maximal and complete state of things... In this sense narrative worlds are parasitical, because, if the alternative properties are not specified, we take for granted the properties that hold good in the real world. In Moby Dick it is not expressly stated that all the sailors aboard the Pequod have two legs, but the reader ought to take it as implicit, given that the sailors are human beings. On the other hand the account takes care to inform us that Ahab had only one leg, but, as far as I remember, it does not say which, leaving us free to use our imagination, because such a specification has no bearing on the story.

Another instance of Eco's dexterity introduces a reservation. Consider the hoary old problem, Why do mirrors reverse left to right and not up to down? Eco talks of mirrors at length, and he gives a short but very confident solution to the problem. (This is itself unusual, since in general Eco cherishes mysteries rather than the solutions of them.) Eco claims that mirrors do not reverse anything at all. He invites us to think not of a mirror but of a "prosthetic eye," a third eye that is situated in our index finger. If we point this at ourselves we will obtain the view that somebody has who is facing us, which, Eco seems to think, is equally the view that the mirror gives us. It is this point of view that "reverses" left to right, but this just means that it is facing in the opposite direction to our normal point of view. In a footnote Eco tweaks the psychologist Richard Gregory:

Gregory also quotes Gardner... who had also made the obvious observation that mirrors do not reverse anything at all. But not even this is enough for Gregory, and he adds another reason for surprise: that mirrors also reverse depth, and that is to say, if we walk away from a mirror, say toward the north, the image moves away from us toward the south, and it gets smaller (I would add that it's hardly likely to come running straight at us). But, Gregory says, mirrors do not reverse concave 
and convex. All you have to do is think of the mirror as a prosthesis, or an eye on the index finger, and it will let me see what I would see if someone were standing in front of me: if that someone moves away, his image gets smaller, but if he has a potbelly, then it will stay that way, nor will the pit of his stomach contract toward the inside.

Again, this is amusing. The playfulness works well. The problem is that a moment's thought shows that if this is Eco's theory, it is incorrect. The view in a mirror is not the view obtained by looking at someone standing in front of you, nor is it the view obtained by an eye looking at you. To see this, hold an ordinary book on your chest and look in a mirror. You will have difficulty reading the writing. But to a person looking at you, the writing reads normally; and if you now ask your partner to hold the book outwards and face you, you have no difficulty reading it either. Mirror-writing does not appear in either of these views. (I say "if this is Eco's theory," because here, and everywhere, he shows a gift for evasion, and it is extremely hard to know with any certainty what he actually believes.)

The passages that I have given are pleasantly humorous. But as Bernard Williams observed a few years ago, Eco's real wit is juxtaposed with things that seem unfunny to a bewildering degree. In the new book, we could contrast the passages that I have just quoted with a long and labored exercise in which Eco draws a "map"-in fact, two maps—of an imaginary town called Vanville. The streets and the landmarks of this town are labeled with names and terms that are found as examples in the writings of the philosopher Quine. The only intellectual point of the exercise, which stretches over ten pages, is to show that it is difficult to locate things by referring to landmarks once the landmarks have vanished. The ulterior motive seems to be to display a cozy intimacy with Quine's writing, and indeed with Quine personally. "Van," he instructs, "is how Willard Van Orman Quine was known to close friends." I do not know whether the claim to intimacy is justified, but the thing is excruciating either way. And why the past tense, since Quine is still among us?

II.

Before we get to Kant or the platypus, Kant and The Platypus begins with a chapter on Being. Here is a fairly typical sample:

As Heidegger says in Being and Time (490), angst constitutes the opening of being-there to its existence as being thrown for its own end; agreed, and the (grammatical) subject of this thrown being is the Dasein. But then why is it said immediately afterward that "because of it [angst], being opens to being-there" and the "being of being-there is totally at stake"? The being of being-there is pure tautology. Being-there cannot be based on something, given that it is "thrown" (why? because it is). Whence comes this das Sein that opens itself to being-there, if the beingthere that opens itself is an entity among the entities? 
Whence, indeed. It would be wrong to ridicule this before explanation, for philosophers must be allowed their bits of terminology. It is much better to ridicule it afterwards.

So: to say that something opens to being-there means that people think about it. We all know about Angst: the fear of death and absurdity and all that. Something is said to be thrown at us if we cannot do anything about it, although admittedly this does not explain why our existence is thrown "for its own end," whatever that may mean. If we want to know what Being is, we will have plenty to look back upon. "Here is what we mean by the word Being: Something." On the other hand, "Being is the horizon, or the amniotic fluid, in which our thought naturally moves." I don't know if I live an unusually cluttered life, but I find it difficult to reconcile these two statements. Something bumped into my car last week, but I don't believe it was either a horizon or an amniotic fluid.

All right, we are not supposed to take it literally; but then we must ask ourselves how we are to take it. Anyhow, "Being is even before it is talked about." Being also pops up in Latin: "Being is id quod primum intellectus concipit quasi notissimum." We have also been told the answer to the question, "Why is there being rather than nothing?" The answer, adverted to above, is: "Because there is." Yet this answer, which Eco insists must be taken "with the maximum seriousness," is in danger of being retired two pages later, when we are equally told that "there is no need to wonder why there is being; it is a luminous evidence."

All this may help the reader to understand the passage that I have cited, or it may not. P.G. Wodehouse talks of family occasions best avoided, when Aunt is calling to Aunt like mastodons bellowing across primeval swamps; and Eco's sparring with Heidegger reminds me of them. In fact, insofar as we can keep score here, it seems to go like this. Heidegger holds that it is only because people are afraid of death that they become self-conscious, or perhaps conscious of the world around them. This is analogous to the Stoics' view that it is only because people are afraid of death that they seek political office and want to have statues erected to themselves. These are not very convincing ideas, but if this is Heidegger's stumbling at a thought, then Eco's reply that consciousness is "thrown," or even "pure tautology," is clearly offtarget. Consciousness and self-consciousness are worth explaining, and an emotion such as the fear of death might be a part of the explanation, unlikely though it sounds.

What has gone wrong? Meditation upon Being has its roots in Parmenides, Plato, Plotinus, Anselm, and Aquinas. It need not be disreputable. What is disreputable is the way these meditations become hijacked by oracular obscurity. Eco collaborates in this obscurity with Heidegger, who at least had the excuse of being a theologian by training. It might seem merely tiresome when intellectuals trick out banal thoughts-nature turns up people who think; sometimes they worry; they think about death; the modern world is 
horrid-in terms of Being, Being-there, Being revealing itself, Angst, and the rest. But in fact it matters a great deal, as the famous double dactyl reminds us:

\author{
Higgledy piggledy \\ Herr Rektor Heidegger \\ Said to his students: \\ "To Being be true! \\ Lest you should fall into \\ Inauthenticity. \\ This I believe- \\ And the Führer does too!"
}

Lament that you have lost the shelter of Being, and soon you start wanting a plan for recovering it. This turns out to require authenticity, which is best discovered through nineteenth-century Romantic visions of inarticulate ancient purity, the Fatherland, blood, and destiny. You then find that the quest requires a political expression, such as the Nazi Party, whose unique rapport with primordial Being was so striking to Heidegger. The sleep of reason produces monsters, and more monsters.

Or as Voltaire said, those who can make you believe absurdities can make you commit atrocities. The good news is that Eco is not dangerous, certainly not dangerous enough to produce monsters; and his interest is not really in ontology or cosmology. The bouts with Heidegger come across as mere certificates of profundity. His real interest is in the nature of signs and cognition.

III.

If there is a central theme in Eco's book, it is the problem of universals, or of the relation between particular things and general categories. Eco introduces this topic by means of cases where we come across things that stretch previous classifications. When Marco Polo arrived in Java, he came across the rhinoceros, and he was able to regard it only as a rather scrubby unicorn. When Spanish cavalry arrived in the New World, Montezuma's subjects did not know what they were seeing, or even whether they were looking at one animal or two.

Kant never came across the platypus, unless possibly by hearsay towards the very end of his life. But Eco is exercised by the question of how Kant might have reacted to a beast that resisted familiar biological categories. I am not sure why this is an interesting question. Like anybody else, Kant would have been faced with the problem of warping his scientific heritage to fit his new experience. It is not clear that the critical philosophy gives him any special understanding of this process, or any reason to conduct it in some special way. In fact, as Eco admits, the question is speculative, for Kant does 
not tell us much about small-scale, everyday empirical concepts, such as "dog" or "chair" (or "platypus"). He is happier with highly abstract concepts, such as substance and time, or space and causation, and even a platypus is a thing that lasts for a time, occupies space, resists penetration, and is subject to gravity.

Still, Eco wishes to link Kant to the platypus. So he directs us to the chapter of the Critique of Pure Reason in which Kant seems to address the way in which concepts become applicable in experience. Even here it is not really clear that Kant intends to be talking about everyday empirical concepts. Kant's chapter is called "The Schematism of the Pure Concepts of Understanding," which certainly suggests otherwise, since the pure concepts of understanding are the big abstract categories. In any case, the chapter was a notorious show-stopper even in Kant's time. Jacobi called it "the most wonderful and most mysterious of all unfathomable mysteries and wonders." Many modern commentators have dismissed it out of hand. Their view is that Kant had set himself an unanswerable question, along the lines of "What is the rule for applying rules to experience?" or "What is the recipe for making use of recipes?" The complaint is that there cannot be a rule for applying rules in general. Any answer would be regressive, having to consist in producing another rule or another recipe, about which the same question would then inevitably be asked.

This moral is often credited to Wittgenstein, who is indeed adept at uncovering hidden regresses in various accounts of our understanding. We are apt to feel, for example, that spontaneous judgments might be explained by our having, in our mind's eye, diagrams or templates or little pictures that tell us what we are looking at. So if I am told to pick a red flower, perhaps I do so by conjuring up my red picture and then picking a flower that bears a sufficient resemblance to the picture. Wittgenstein's comment on this in The Blue Book is lethal-one of the best short refutations in philosophy:

But this is not the only way of searching and it isn't the usual way. We go, look about us, walk up to a flower and pick it, without comparing it to anything. To see that the process of obeying the order can be of this kind, consider the order "imagine a red patch." You are not tempted in this case to think that before obeying you must have imagined a red patch to serve you as a pattern for the red patch which you were ordered to imagine.

Wittgenstein points out that there has to be a stop to producing interpretations of words (or diagrams or images). There has to be a point at which we just go ahead and do what we were told, without consulting any mental diagrams or templates or words at all.

Yet this is also a point that Kant himself makes, immediately before the notorious chapter on schematism. So charity seems to require that we find something for Kant to be doing other than committing the mistakes against which he has just warned us. The best suggestion, I believe, takes seriously his own warning that he is talking about "an art concealed in the depths of the 
human soul, whose real modes of activity nature is hardly likely ever to allow us to discover, and to have open to our gaze." That art is the art of judgment, and the reason that it is concealed in the depths of the soul is precisely that it cannot be reduced to the grasp of rules, or recipes, or criteria. Nor can it be reduced to the presence, before the mind, of a thing like a picture or a even a word, and for Wittgenstein's reason. Even when pictures, diagrams, and words float before our mind's eye, judgment only comes about when we have taken them the right way. Judgment then requires something spontaneous, outside the domain of reason; but this "something" is a pre-condition for making any application of reason.

This can all sound very mysterious. We are not comfortable with arts concealed in the depths of the soul. But what we are facing is bedrock, the unthinking deployment of customs and routines that make up the way in which we are usually at home in the world. When it comes to recognizing things, we just do it. Common sense and philosophical reflection really cannot tell us any more. There can be a further science of the functions of the brain that enable us to just do it, and of course there exist remarkable data on what happens when those functions are damaged; but Eco is explicit that he intends to offer no contribution to any such science.

What, then, is Eco doing? He talks at length of the particular and the general, and of the nature of symbolization, but it is never clear that he has grasped Wittgenstein's point or Kant's point. He reverts constantly to the idea of us applying a diagram, or an icon, or a schema, as if this were the essential but mysterious element in explaining the process of judgment. Perhaps semiotics is an open invitation to this idea. Semiotics is the study of what occurs when one thing is a sign of another thing. To suppose that it is fundamental to cognition, then, is to suppose that cognition is essentially a matter of comparing one thing with another; but this is precisely the model that Wittgenstein and Kant oppose.

\section{IV.}

It is hard to tell what is going on here, and it is equally hard to tell whether Eco is addressing mysteries or manufacturing them. Still, this is not always the case. Perhaps unwisely, Eco does engage, confidently and combatively, with relatively clear themes of modern philosophy. And here a more definite verdict is possible.

Prominent literary intellectuals often like to make familiar reference to the technical terminology of mathematical logic or the philosophy of language. A friend of mine overheard the following conversation in Cambridge during l'affaire Derrida, when the proposal to grant an honorary degree to that gentleman met serious opposition. A journalist covering the fracas asked a Prominent Literary Intellectual what he took to be Derrida's importance. "Well," the PLI confided graciously, unblushingly, "Gödel showed that every 
theory is inconsistent unless it is supported from outside. Derrida showed that there is no outside."

Now, there are at least three remarkable things about this. First, the thing that Gödel was supposed to show could not possibly be shown, since there are many demonstrably consistent theories. Second, Gödel indeed did not show it, and he did not purport to do so. Third, it makes no sense to say that an inconsistent theory could become consistent by being "supported from outside," whatever that might mean. (Inconsistency sticks; you cannot get rid of it by addition, only by subtraction.) So what Derrida is said to have done is just as impossible as what Gödel was said to have done.

These mistakes should fail you in an undergraduate course on logic or mathematics or philosophy. In the world of the PLI, however, they are minor considerations. In his world, the mere mention of Gödel, like the common invocation of "hierarchies" and "metalanguages," gives a specious impression of something thrillingly deep and thrillingly mathematical and thrillingly scientific. And it gives the PLI a flattering image of being something of a hand at these difficult but deep things, an impresario of the thrills. I expect that the journalist swooned.

Eco is not in the same league as my PLI. He has taken the trouble to read a good deal of the modern philosophy of language. He talks familiarly of Quine, Putnam, Davidson, and Kripke. Perhaps the Anglo-American tradition should be grateful for this, since few figures in continental Europe take this trouble. He also remarks intelligently upon real problems for some positions in the Anglo-American tradition, notably the problems of fictional and empty names. And yet Eco has a disturbing tendency to go right off the rails. I apologize in advance for needing a little bit of detail to show this, but it is Eco who has strewn the technicalities in the path of his audience.

A good example is Eco's use of the notion of "rigid designation." This is a technical term due to Saul Kripke. It describes a feature belonging to names and indexical expressions ("this," "I," "here") in natural languages, and it distinguishes them from other referring expressions, notably descriptions ("the first dog born at sea," "Kant's hometown"). In a nutshell, the "rigidity" in question means that when you use a name, even to talk about strange and different possibilities, you are still interpreted as talking about whatever it is to which the name actually refers. So if I say, "Had the political boundaries been slightly different, the people of Königsberg might have spoken Latvian," I am still talking about that very town, Königsberg. But if I say, "Had his parents moved south, Kant's hometown might have been Berlin," the description "Kant's hometown" has become detached, as it were, from Königsberg. For I am not trying to say that had Kant's parents moved south, Königsberg might have been Berlin. I am saying that Berlin is where he might have been born and raised. This is what is meant by saying that descriptions are not rigid, whereas names are rigid.

Eco talks a great deal about rigid designation. Unfortunately, he identifies it by the ambiguous formula that a rigid designator refers to the same thing "in 
all possible worlds," and then takes that formula in the wrong sense, as meaning that there is no possibility of the same name referring to something different. This is a misunderstanding against which Kripke explicitly and clearly warned. Given this misinterpretation, of course, the idea of rigid designation would be outrageous, since you can always take a term and use it to refer to something different. People like to give their pets names such as "Aristotle" or "Toscanini." It is particularly bizarre of Eco to think that Kripke and the tradition following him failed to notice that the indexical "this" may refer to different things on different occasions. It would be as if having said, pointing to one flower, "This is a rose," you could not go on to say, pointing to another flower, "But this is a daffodil."

The blunder leads Eco to suppose that rigid designation is "independent of all knowledge or intention or belief on the speaker's part." It leads him to some strained speculations about the reference of terms being fixed by the Divine Mind or the Infinite Mind, as if it were God who forges the link between names and things. It also leads him to misunderstand another celebrated episode in modern philosophy of language. The philosopher Hilary Putnam once proposed a "twin-earth" thought experiment, in which we imagine an earth just like this one, except that the stuff playing the role of water is some different chemical, called $X Y Z$. We can imagine, according to Putnam, the persons on twin-earth talking happily of "water." Eco interprets Putnam as proposing that persons on twin-earth would thereby be referring to water, or $\mathrm{H} 2 \mathrm{O}$, because he takes rigidity to imply this. But Putnam's point was exactly the opposite, namely, that they would not be referring to water, but would be referring to the stuff that surrounds them, to $X Y Z$, which is not water but a good substitute for it. Eco not only gets this wrong, he even implies that Putnam is somehow inconsistent, having forgotten his own earlier opposition to the idea that reference is fixed somehow by magic, by something outside of us like a Divine Mind.

On another occasion Eco squares up to one of the most famous papers in modern philosophy, Quine's "Two Dogmas of Empiricism," which appeared in 1951. In that paper, Quine attacked the entire positivist program as dependent on two carefully described dogmas. Later, in 1973, in an almost equally famous paper called "On the Very Idea of a Conceptual Scheme," Donald Davidson claimed that even a sanitized empiricism, free from Quine's two dogmas, depended on yet a third dogma. Eco presents himself as knowing all this. "I am well aware," he writes, "that advocating the existence of observation sentences independent of a general system of propositions was said by Davidson to be the third dogma of empiricism..."

The problem is that it wasn't. That was Quine's second dogma of empiricism, the one that he called reductionism, and to which his counter was that "our statements about the external world face the tribunal of sense experience not individually but only as a corporate body." Davidson's third dogma of empiricism was that there is a defensible dualism of "scheme and content"-a distinction between the world waiting to be organized, and the conceptual 
scheme that does the organizing. And, like Kripke, Davidson explicitly insisted on the distinction in the course of introducing his third dogma.

Anyone can make a slip, but I suspect that Eco could not bring himself to face Davidson's third dogma fairly and squarely, because he is heavily invested in it himself. $\mathrm{He}$ is constantly speculating on how the mind uses categories, schemata, cognitive types, language, and inference in order to organize and to impose order on an undifferentiated "continuum." Or perhaps semiotics encourages an ability to misread. There certainly are other examples: I would have liked to add an account of Eco's nightmarish attempt to engage with the Polish logician Alfred Tarski, but that is not suitable for family enjoyment.

VI.

Does all this matter? To anyone who knows anything about Kripke, Putnam, Quine, or Davidson, these things seem like the thirteenth strike of the clock, the one that casts doubt on all the rest. But Eco brushes the details aside, and his intended audience is unlikely to be any the wiser. In the wider scheme of things, some might think that it doesn't really matter if here and there a PLI goes astray. If all you want to do when you have the stick is twirl it around in the carnival, then it is not important whether you get hold of the wrong end of it.

Whatever else it may be, Eco's playfulness is certainly a good defensive posture. It makes it hard for the critic to take a stand, and harder still for the audience to admit that any shortcoming may be involved in its admiration of the work. You cannot effectively criticize the Alice books on the grounds that they make no sense, for this is a part of their charm. In Eco's case, however, the lapses of sense are not a part of the charm. His words are presented as if they are to be taken seriously, as a contribution to a little bit of science, a modest chamber in the storehouse of valuable human thought. And they may be so taken by many, including their author.

The problem here is not the hip, glib, parodic style of a postmodernism that has fundamentally nothing to say. But it has similar roots. In a famous review in the philosophical journal Mind in 1961, P.B. Medawar talked of the bogus misuse of biology and evolutionary theory in Teilhard de Chardin's The Phenomenon of Man, and asked how it could ever have gained an audience. He perceptively identified the state of mind that is required for its admiration as, "Really it's beyond my poor brain, but doesn't that just show how profound and important it must be?" This is an intellectual version of passiveaggressive syndromes in psychology - an attitude very much like taking pride in one's own abasement. The novice is to trust the master all the more because the master humiliates him; and his trust in the master numbers him with the elect.

I draw the comparison with the novitiate because until we make it, we might be merely irritated by some of the more overt discourtesies of Eco's 
book. He provides no translations of other languages, and Latin especially is strewn around liberally. His book is marketed as a book for the general reader, not as a specialist monograph. Yet it presumes that the reader is acquainted with things such as Peirce's philosophical terminology-something that almost nobody understands. It also presumes an acquaintance with difficult and technical logic, and with the philosophy of language. Eco also makes an unappetizing number of references to his own previous works and skirmishes with fellow semioticians. Very, very few readers will not be insidiously humiliated.

And we can now see that this humiliation is deliberate, like the hazing routines in a fraternity. The audience for a book such as this one must want to enjoy its own bewilderment. At the same time, however, the audience is not supposed to think of this as playtime. It is not like the proper audience of the Alice books, which might enjoy its own confusion, just because it enjoys testing the boundaries of ordinary logic and ordinary courses of events. The proper audience for Carroll has to be perceptive, in a way that the proper audience of Eco (or Teilhard) must be blind. This cannot be an audience educated into thinking. It must take active pleasure in the sleep of reason, and take comfort in the presence of mysteries.

It is important to realize that the fault has almost nothing to do with an affinity for one school of philosophy rather than another. After all, Eco is marvelously eclectic. Nor does it have anything to do with the alleged right of the intellectual to imitate the scientist, by adopting technical terms and difficult vocabularies. The mental suffocation that I have described is not usually due to difficult vocabularies. Yet Eco can leave you for pages distressed or infuriated because you do not know if he has got hold of a real problem, or what he is really trying to say about it. The fault, I believe, is a kind of literaryphilosophical conceit, an obscurantist knowingness, a complacency that blurs the difference between genuine mastery of a technique and the self-deceived appearance of it.

When I finished reading Eco's book, I had a recurring image of the Roadrunner cartoons, in which Wile E. Coyote is forever finding himself running off the edge of the cliff. He stays up so long as he keeps running, so long as he does not look down. Umberto Eco never looks down. And if he refuses to notice the cliff, perhaps he is right to think that his audience will also not notice it. In this, like the platypus, he has adapted himself perfectly to a particular environment-in this case, an intellectual environment. But what he has produced should make us deeply worried about that environment, which is much bigger and more ubiquitous even than he is.

Simon Blackburn

Dept. of Philosophy

Univ. of N. Carolina, Chapel Hill, USA

sblackbu@email.unc.edu 